\title{
Cytohistopathological correlation of Papanicolaou smears: a hospital based study
}

\author{
Purwa Rangrao Patil*, Shubhangi Narayan Jibhkate
}

Department of Pathology, Grant Government Medical College and Sir JJ Groups of Hospitals, Byculla, Mumbai, India

Received: 25 April 2016

Accepted: 02 May 2016

\section{*Correspondence:}

Dr. Purwa Rangrao Patil,

E-mail: patil.purwa@gmail.com

Copyright: (c) the author(s), publisher and licensee Medip Academy. This is an open-access article distributed under the terms of the Creative Commons Attribution Non-Commercial License, which permits unrestricted non-commercial use, distribution, and reproduction in any medium, provided the original work is properly cited.

\begin{abstract}
Background: Carcinoma of cervix is the second most common cancer in women worldwide and the leading cause of death from cancer in several developing countries including India. The use of the cervical smear (Papanicolaou/Pap) as a screening tool has significantly reduced the incidence of cervical cancer. Cytohistopathological correlation of Pap smear is a widely accepted method of internal quality assurance and helps in the analysis of various factors leading to discrepant diagnosis. With the above view, the present study has been carried out to evaluate the cytohistopathological correlation of the various cervical lesions.

Methods: The study was prospective cross-sectional hospital based study carried out over a period of eight months in which out of 500 pap smears screened, cytohistopathological correlation of 70 cases were obtained.

Results: Specificity in the present study was $84.2 \%$ and the sensitivity was $77.7 \%$. The accuracy of Pap smears was $82.1 \%$. The overall correlation between cytology and histopathology was found to be $57 \%$ with the highest correlation in the high grade squamous intraepithelial lesion (HSIL) category (87.5\%).

Conclusions: The study provides good cytohistopathological correlation especially for high grade lesions. So we believe that the success of screening for cervical cancer is based on collection of adequate materials and correct interpretation of abnormal cells.
\end{abstract}

Keywords: Carcinoma cervix, Pap smears, Cytohistopathological, Correlation, HSIL, LSIL

\section{INTRODUCTION}

Cancer of uterine cervix is the second most common cancer worldwide next to breast cancer and most common female cancer in many developing countries like India. ${ }^{1}$ WHO global report 2014 states 266000 women died from cervical cancer in year 2012. ${ }^{2}$ The age adjusted incidence rates (AARs) of cancer cervix has decreased in the urban Indian population. However, over 70 per cent of the Indian population resides in the rural areas; cancer cervix still constitutes the number one cancer in India. ${ }^{3}$ Human papilloma virus (HPV) is recognized as the primary causal factor in the development of cervical cancer. ${ }^{4}$ The accessibility of the uterine cervix with propensity of its cells to exfoliate and a prolonged natural history of the premalignant lesions provides the best potential for the control of a cancer by population screening. Although Papanicolaou (Pap) cytology represents the most effective technique to prevent and detect the precancerous conditions of the uterine cervix before they become invasive cancer, its false negative yield due to the potential sampling and interpretation errors yield is still a reason of concern. Thus, the final diagnosis should be made on histologic examination to assess the accuracy of the cervical cytology. Cytohistopathological correlation of Pap smear is one of the recommendations of the European guidelines for quality assurance for the development of cytology laboratory performance and, in particular, to reduce falsenegative results. ${ }^{5}$ With the above view, the present study 
has been carried out to evaluate the cytohistopathological correlation of the cervical lesions. It aimed at studying the incidence of various cervical abnormalities such as infections, dysplasia; conforming the diagnoses by histological examination and evaluating the accuracy of cervical cytology in the assessment of pre-invasive and invasive lesions of the uterine cervix.

\section{METHODS}

This prospective cross-sectional diagnostic test hospital based study was conducted in tertiary care hospital, over the period eight months. The study was approved by hospital based ethical committee. Out of 500 pap smears screened, 70 cases were selected whose corresponding histopathological sample was also received in the form of the cervical biopsy or hysterectomy performed for various medical indications. The study group included women from different age groups coming from a low socioeconomic background who was attending the gynecology out-patient department (OPD) for varying complaints. The Pap smears were taken with the Ayer's spatula on a clean glass slide and fixed immediately in 95\% ethanol and ether equal parts. Staining of the slides was performed by means of the conventional Pap technique was reported in accordance with the Bethesda system 2001. Tissue material was fixed in $10 \%$ neutral buffered formalin solution and processed routinely with final embedding in paraffin blocks and stained with hematoxylin and eosin ( $\mathrm{H}$ and $\mathrm{E}$ ). Both the cytology and histology slides were examined by two qualified pathologists in a double-blind fashion.

\section{RESULTS}

The mean age of the patients was 38 years \pm 10.7 SD (range: 24 to 65 yrs.). Incidence of normal smears in the present day study was $11.4 \%$. Majority of the patients who underwent Pap smears had evidence of infection (41.4\%) including $5.7 \%$ of Trichomonas infections and $2.85 \%$ due to Candida albicans.

There were 9 cases of LSIL (Low grade squamous intraepithelial lesion) and 8 cases of HSIL (High grade squamous intraepithelial lesion) amounting to $12.8 \%$ and $11.4 \%$ respectively. One case of carcinoma was accurately diagnosed by the screening procedure. Majority of the patients of carcinoma cervix were in the $4^{\text {th }}$ decade of life indicating a trend affecting younger population.

$20 \%$ slides were considered to be inadequate when classified according to the Bethesda system in which one case of carcinoma was missing in the Pap smear due to inadequate cellularity. Observations are summarized in Table 1.

Specificity in the present study was $84.2 \%$ and the sensitivity was $77.7 \%$. The accuracy of Pap smears was $82.1 \%$. The overall correlation between cytology and histopathology was found to be $57 \%$ with the highest correlation in the HSIL category $(87.5 \%$ ) (Figure 3, 4).

Table 1: Summary of Pap smear cytology and histology findings.

\begin{tabular}{|lllllllll|}
\hline PAP & NAD & Cervicitis & CIN 1 & CIN 2 & CIN 3 & Ca in-situ & Carcinoma & Total \\
\hline Normal & 2 & 5 & - & - & - & - & - & $7(3)$ \\
\hline Inflammatory & 6 & 19 & 4 & - & - & - & - & $29(3)$ \\
\hline ASCUS & - & 1 & - & - & - & - & - & 1 \\
\hline LSIL & 1 & 3 & 3 & 1 & - & - & 1 & $9(2)$ \\
\hline HSIL & - & 1 & - & 3 & - & 1 & 3 & 8 \\
\hline Carcinoma & - & - & 1 & - & - & - & 1 & 2 \\
\hline Inadequate & 3 & 8 & 1 & - & 1 & - & 1 & $14(2)$ \\
\hline Total & $12(2)$ & $37(10)$ & $9(5)$ & $4(1)$ & 1 & $1(1)$ & 6 & 70 \\
\hline
\end{tabular}

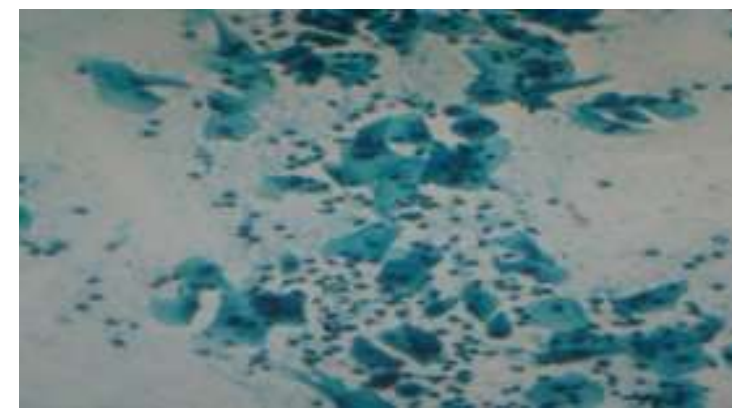

Figure 1: Pap smear showing mild inflammatory atypia (40X).

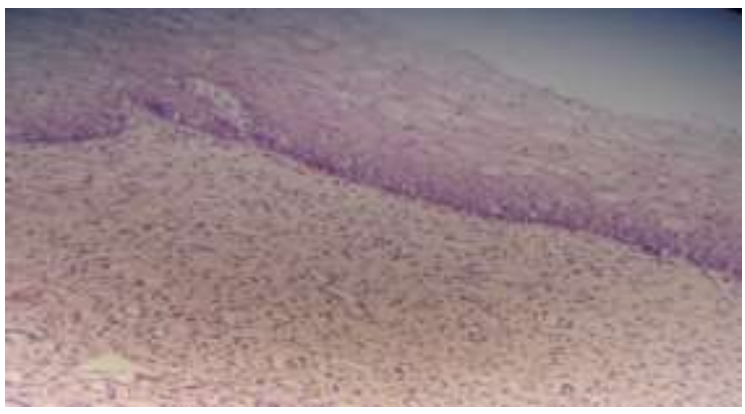

Figure 2: Cervix biopsy showing chronic cervicitis and koilocytic change (H and E, 40X). 


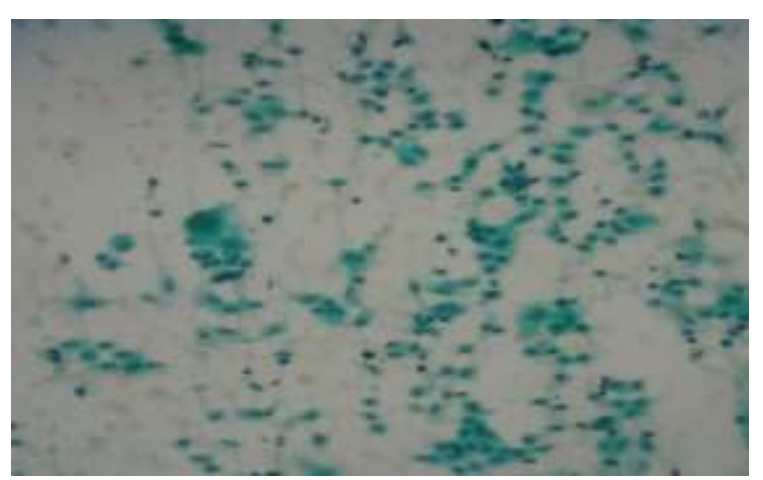

Figure 3: Pap smear showing high grade atypia (40X).

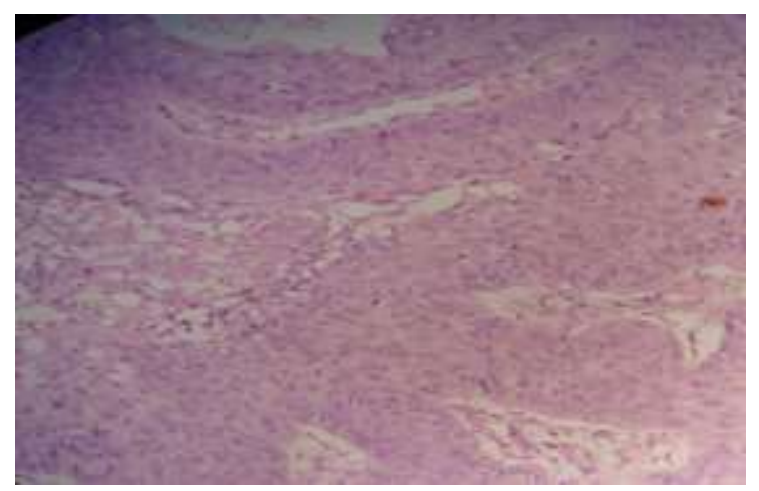

Figure 4: Cervix biopsy showing carcinoma in-situ (H and E, 40X).

$1.4 \%$ atypical squamous cells of undetermined significance (ASCUS) were seen in the Pap smears. Koilocytosis was found in $14.3 \%$ of the Pap smears as against $27.2 \%$ on histopathologic examination (Figure 1, 2).

\section{Parameters}

\section{Sensitivity}

Specificity

$77.7 \%$

Positive Predictive Value

$84.2 \%$

$70.0 \%$

$\begin{array}{ll}\text { Negative Productive Value } & 88.8 \% \\ \% \text { of false negatives } & 22.2 \%\end{array}$

$\%$ of false positives $\quad 15.7 \%$

Accuracy

$82.1 \%$

\section{DISCUSSION}

Most cervical cancers start from an area of dysplastic epithelium (transformation zone) which can be detected well by taking a good Pap smear, the best screening programme worldwide recommended for sexually active women. $^{6-8}$ This most widely used screening test as of today is simple and acceptable, but it has been found to have falsely high negative results ranging from 1.1-30\%, Chhabra et al $2003(18.7 \%)$, Ozkara et al $2002(5.3 \%)^{9,10}$ The false negatives of our study were $4(22 \%)$. All these were LSIL cases. These variations have been attributed to difference to cytological expertise, variation in sampling techniques and preparation of the smear. Another important factor in the malignant lesions does not exfoliate at a constant rate. The other problems which led to under calling include air drying, inflammatory reaction and obscuring blood also noted. However, no case of HSIL or carcinoma was missed cytologically.

These results are basically comparable to those reported in other major series using cytohistologic comparison and regarding sampling error and preparation artifact like drying artifacts, inadequate fixations, background materials and thick smears are the most common source of the false negative smears, screening and interpretation mistakes being relatives uncommon. ${ }^{11,12}$ Because false negative rates are usually underestimated when using follow up controls, our value observation against immediate histologic 'gold-standard' reflects an adequate and effective screening program for cervical cancer. ${ }^{13}$

Collecting material for cytology with an endocervical brush and the new Pap smear screening techniques using liquid based Pap (thin-prep Pap, autocyte PREPTM System) appear to increase sensitivity as this techniques prevent air drying artifacts, have minimum background material and increase the cellularity. ${ }^{14}$ It also offers the possibility of HPV, DNA testing with hybrid capture technology especially performed in cellular residues of the liquid based cytology collection kits which appears to be most cost effective (Ferenzy 1997). ${ }^{15}$

Alwahaibi et al shows false positive in $32.2 \%$ while Abali $\mathrm{R}$ et al show $43.0 \%$ false positives. ${ }^{16,17}$ In the present study, the 6 cases of false positive smears (15.7\%) were also reexamined. 4 were diagnosed as LSIL, 1 as ASCUS and 1 as HSIL. In these cases biopsy examination failed to demonstrate any tissue abnormality and smear reviews confirmed the presence of abnormal cells. This might be explained by the occasional inaccuracy of cervical biopsy in detecting focal lesions, especially of mild degree and those lesions located in difficult to sample areas such as the inner cervical canal. A colposcopically guided cone biopsy may be a solution to this and must therefore be advocated whenever possible.

After the introduction of the Bethesda system few new confusions and questions have been raised. One among them is regarding the significance of ASCUS. The incidence of ASCUS in present study was $1.4 \%$ while Naik et al 2015 showed $2.8 \%$ incidence as opposed to Mihaela et al 2011 who reported very large proportion of ASCUS cases $47.9 \%$. $^{18,19}$

In terms of diagnostic group discrepancy, a two category discrepancy occurred in few cases suggesting that this is a true problem in cytopathology. ${ }^{13}$ The proportional distribution of their cases into ASCUS, ASCUS-H or LSIL suggests that different factors ultimately influence the proper cytological interpretation of abnormal cells. In our experience, the clinical impact of discordance is limited, because of these cases; we routinely recommend 
a repeat Pap smear before any further therapy such as cone biopsy or hysterectomy.

Therefore, our study showed that the sensitivity rate of cervical cytology screening is high $(77.7 \%)$ especially in detecting HSIL (87.5\%) when specimens are adequate. This is in comparison to studies like of Jain et al with sensitivity of $78 \%$ or $76 \%$ in the Saha et al study. ${ }^{20,21}$

Likewise, in the study by Jain et al, specificity was only $26.9 \%$ while Saha et al showed $83.3 \%$ specificity which was $84.1 \%$ in our study. ${ }^{20,21}$ As shown in Table 2, Nawaz et al (2005) showed 74\% correlation while Rasbridge et al (2005) showed $81.2 \%$ correlation between cytology and biopsy in their study which was $57 \%$ in the present study and which was increased to $92.8 \%$ within one degree of histopathological abnormality. ${ }^{22,23}$ The overall accuracy of Pap smear reporting was $84.6 \%$ by Naik et al whereas the present study showed $82.1 \%$ accuracy. ${ }^{18}$

Nevertheless relatively low correlation of accepted, histologically specific cytologic classification with the biopsy diagnoses is disappointing and raising some question as to the reliability of the very specific cytologic diagnosis is borderline lesions.

Table 2: Comparison of Pap smear values in different studies (\%).

\begin{tabular}{|llllll|}
\hline Study & Sensitivity & Specificity & PPV & NPV & Diagnostic accuracy \\
\hline Saha et al, 2005 & 76 & 83.3 & 86.4 & 71.4 & 79.4 \\
\hline Bruce et al, 1996 & 89.4 & 64.8 & 88.9 & - & - \\
\hline Naik et al, 2015 & 79.4 & 58.3 & 86.1 & 46.6 & 74.5 \\
\hline Di Bonito et al, 1993 & 76.3 & 93 & 80.2 & 91.3 & \\
\hline Present study & 77.7 & 84.1 & 70 & 88.8 & 82.1 \\
\hline
\end{tabular}

\section{CONCLUSION}

In conclusion we believe that the success of screening for cervical cancer is based on collection of adequate materials and correct interpretation of abnormal cells. Therefore better awareness, motivation programs along with the use of thin-Prep Pap liquid based cytology technique to reduce inadequate sampling errors and the HPV, DNA testing for early detection of cervical lesions is recommended for a virtual $100 \%$ prevention of cervical cancer in the years to come.

Funding: No funding sources

Conflict of interest: None declared

Ethical approval: The study was approved by the Institutional Ethics Committee

\section{REFERENCES}

1. GLOBOCAN 2008 (IARC), Section of Cancer Information (8/10/2012). (WHO, 2009b; GLOBOCAN 2002 database, IARC.

2. Comprehensive cervical cancer controls a guide to essential practice. $2^{\text {nd }}$ edition. World Health Organization 2014. Available at http:appswho.int/iris/bitstream/10665/144785/1/978 92411548953_eng.pdf. Accessed 15 August 2015.

3. Nandakumar A, Ramnath T, Chaturvedi M. Indian J Med Res. 2009;130(9):219-21.

4. NIH Consensus Development Conference Statement, 1996. WHO/EUROGIN Joints Experts Meeting Cervical cancer screening, 1996.

5. Wiener, HG, Klinkhamer P, Schenck U, Arbyn M, Bulten J, Bergeron C, et al. European guidelines for quality assurance in cervical cancer screening: recommendations for cytology laboratories. Cytopathology. 2007;18(2):67-78.

6. Imtiaz F, Hasa WHG, Klinkhamer P, Schenck U, Arbyn M, Bulten J, et al. European guidelines for quality assurance in cervical cancer screening: recommendations for cytology laboratories. Cytopathology.2007;18(2):67-78.

7. Saslow D, Runowicz CD, Solomon D, Moscicki AB, Smith RA, Eyre HJ, et al. American Cancer Society Guidelines for the early detection of Cervical neoplasia and cancer. CA Cancer. 2002; 52:342-62.

8. Sawaya GF, Brown AD, Washington AE, Garber AM. Clinical practice: current approaches to cervical cancer screening. N Engl J Med. 2001; 344:1603-7.

9. Chhabra Y, Behera BG, Khalkho J, Pati N. Cytomorphological study of PAP smears in precancerous and cancerous lesions. J Cytol 2003; 20(2):64-7.

10. Ozkara SK, Yildız K. Retrospective five year analysis of our servicovaginal cytology screening programme under the perspective of Bethesda-2001. Turkish Bulletin of Pathology. 2002;19:119-24.

11. Yeah GP, Chan KW. The Accuracy of Papanicoaou smear predictions: cytohistological correlation of 283 cases. Hong Kong Med J. 1997;3:373-6.

12. Gupta S, Sodhani P. Why is high grade squamous intraepithelial neoplasia under-diagnosed on cytology in a quarter of cases? Analysis of smear characteristics in discrepant cases. Indian J Cancer. 2004;41(3):104-8. 
13. Husain OAN. Butler E, Evans DMD. Mac JE, Yule R. Quality control of cervical cytology. J Clin Pathol. 1974;27:935-44.

14. Kontzoglou K, Moulakakis KG, Konofaos P, Kyriazi M, Kyroudes A, Karakitsos P. The role of liquid-based cytology in the investigation of breast lesions using fine-needle aspiration: a cytohistopathological evaluation. J Surg Oncol. 2005;89(2):75-8.

15. Frenczy A. The Bethesdab System (TBS): advantages and pitfalls. In: Franco E. New developments in cervical cancer screening and prevention. $1^{\text {st }}$ edition. Europe: WileyBlackwell;1997:151-158.

16. NY Alwahaibi, Sulimi SK, Bai UR. Cytohistological correlation and discrepancy of conventional Papanicolaou smear test with corresponding histopathology: a retrospective study over a 5-years period. East Medit Health J. 2015;21:579.

17. Abali R, Bacanakgil BH, Celık S, Aras O, Koca P, Boran B, et al. Histopathological correlation of squamous cell abnormalities detected on cervical cytology. Turk Patoloji Derg. 2011;27(2):144-8.

18. R Naik, M Minj, R Panda, S Satpathi, PK Behra, K Panda. Cytohistopathological correlation and accuracy of the Pap Smear test in diagnosis of cervical lesions: a hospital based cross sectional study from Odisha, India. Medical Science. 2015;3(3):242-9.
19. Mihaela M, Simionescu C, Ghica P, Desdemona S. Evaluation of Pap-test Performance by a Cytohistopathological and Immunocytochemistry Study with Therapeutic implications. Annals of RSCB. 2011;16(2):42-9.

20. Jain V, Vyas AS, Neoplasia Cyto-Histological correlation (Bethesda system) a study of 276 cases. J cyto Histo. 2010;1:106.

21. Saha R, Thapa M. Correlation of cervical cytology with cervical histology, Kathmandu Univ Med J. 2005;3:222-4.

22. Nawaz FHAQ, Aziz AB, Parvez S, Rizvi J. Prevalence of abnormal papani calaou smears and cytohistological correlation. a study from Aga khan university hospital, Pakistan. Asia Pacific J Clinic Onco. 2005;1(4):128-32.

23. Rasbridge S. One year Audit. Acta cytological. 2005;39:648-1.

24. Bruce A, Jones, David A, Novis. MD Cervical Biopsy-cytology correlation. a college of American pathologist probe study of 22439 correlations in 348 laboratories. Arch Pathol Lab Med. 1996;120:523-1.

25. Di BL, Falconieri G, Tomasic G, Colautti I, Bonifacio D, Dudine S. Cervical cytopathology-an evaluation of its accuracy based on cytohistologic comparison. Cancer. 1993;72:3002-6.

Cite this article as: Patil PR, Jibhkate SN.

Cytohistopathological correlation of Papanicolaou smears: a hospital based study. Int J Reprod Contracept Obstet Gynecol 2016;5:1695-9. 